\title{
Assessment of physical and sexual quality of life in women undergoing planned hysterectomy in tertiary care hospital
}

\author{
Archana Kumari $^{1 *}$, Sunita Malik ${ }^{1}$, Jugal Kishore ${ }^{2}$ \\ ${ }^{1}$ Department of Obstetrics and Gynecology, Vardhman Mahavir Medical College and Safdarjung Hospital, New Delhi, \\ India \\ ${ }^{2}$ Department Community Medicine, Vardhman Mahavir Medical College and Safdarjung Hospital, New Delhi, India
}

Received: 04 April 2021

Revised: 08 May 2021

Accepted: 10 May 2021

\section{*Correspondence:}

Dr. Archana Kumari,

E-mail: archana23priya@gmail.com

Copyright: (C) the author(s), publisher and licensee Medip Academy. This is an open-access article distributed under the terms of the Creative Commons Attribution Non-Commercial License, which permits unrestricted non-commercial use, distribution, and reproduction in any medium, provided the original work is properly cited.

\begin{abstract}
Background: The objective of the study was physical and sexual quality of life (SQOL) in women undergoing elective hysterectomy following six months after surgery.

Methods: This was a prospective observational study in which all women undergoing elective hysterectomies in the department and fulfilling inclusion criteria through any routes and benign indication were recruited after taking informed written consent. Women with endometriosis, previous pelvic surgery and emergency hysterectomies were excluded from study. Each woman was subjected quality QOL questionnaires-SF-36 and SQOL-F prior and six months after surgery. Questionnaires used were in their own language, validated and already tested in pilot study. The required sample size was 65 (taking 20\% lost to follow up) by using Epi-info software, total 78 eligible women taken in the present study. All data was recorded on excel spread sheet and analysis done by SPSS-21.0 and Wilcoxon-test as appropriate.

Results: All aspects of physical and sexual quality of life was found to have improved following hysterectomy. However, only emotional wellbeing worsened.

Conclusions: Hysterectomy improves physical and sexual quality of life post-surgery but sexual quality of life improves more in abdominal route than vaginal route.
\end{abstract}

Keywords: Hysterectomy, Role of limitation due to physical health, Role of limitation due to emotional health

\section{INTRODUCTION}

Hysterectomy is surgical removal of uterus, and it is most widely performed gynaecological surgery. ${ }^{1-3}$ Worldwide, incidence of hysterectomy is $10-20 \%$ whereas in India it has been reported as $4-6 \% .{ }^{4}$ About more than half of all hysterectomies are performed because of abnormal uterine bleeding, which is associated with a wide range of diagnosis that include Uterine fibroids, adenomyosis and abnormal uterine bleeding. ${ }^{5-8}$
Abnormal uterine bleeding (AUB) is bleeding from uterine corpus that is abnormal in frequency, regularity, duration and volume of flow in the absence of pregnancy or associated medical conditions. Hysterectomy is not indicated unless bleeding is persistent, severe and unresponsive to hormonal therapy. Adenomyosis is the case when the uterus is bulky and presents with menorrhagia and dysmenorrhoea. ${ }^{2,4,7}$ Total hysterectomy is done in almost all such cases. Symptomatic vaginal relaxation, uterine descent, and prolapse are common indications for hysterectomy. Uterine leiomyomas accounts for about $30 \%$ of hysterectomies. ${ }^{8-10}$ Although 
hysterectomy is usually done to improve patient's quality of life yet it has its own morbidity and mortality. ${ }^{11-13}$ Hysterectomy related physical co-morbidity typically includes increased risk of developing pelvic floor prolapse, urinary incontinence and sexual dysfunction. ${ }^{19}$ The uterus and cervix are important factors in the physiology of sensation and orgasm, which is affected by sensory stimuli from contractions of the uterus, cervix, and vagina. ${ }^{6}$ Hysterectomy may have a negative influence on this feedback system in the brain. Changes depend not only on which nerves were severed by the surgery, but also the genital regions whose stimulation the woman enjoys for eliciting sexual response because clitoral sensation (via pudendal and genitofemoral nerves) should not be affected by hysterectomy. ${ }^{14}$

Weight gain is not a common result of hysterectomy. Constipation may occur due to lack of muscle tone. Urinary symptoms such as leaking of urine may occur due to lack of muscle tone. Abdominal pains and other pains for example backache, may be experienced during the early days at home until strength is regained. Vaginal bleeding diminishes and become brownish rather than bright red in colour before ceasing altogether. Many women experience a few hot flushes during their early convalescence due to disturbance of the organs during operation. Sexual activities may be resumed when the patient feels ready, and according to the surgeon's instructions. ${ }^{18}$ There may be slight soreness the first couple of times, but this will soon disappear. Sexuality is a dynamic process with a high degree of subjectivity and overlapping that imposes difficulties when it comes to assessing each factor involved in the sexual response. ${ }^{15-17}$

Worldwide only few studies have used validated quality of life questionnaires in women undergoing hysterectomy. As different methods of quality of life assessment were used, the studies could not be pooled, as was demonstrated in a recent meta-analysis on the subject. In 2003, an expert committee on quality of life recommended use of the SF36 health survey in studies comparing post hysterectomy health status. ${ }^{8}$

Not many Indian studies have incorporated quality of life measurement in different type of hysterectomy. Furthermore, in only few trials ${ }^{2,8}$ validated quality of life questionnaires were used, which have also reported varied results. The data regarding the impact of hysterectomy on women's sexual functioning are also not clear and consistent. So, we proposed to do this study to assess the effect of hysterectomy on quality of life using validated questionnaires which was includes physical, emotional as well as sexual aspects of subject.

\section{METHODS}

This was a prospective observational study in which all women undergoing elective hysterectomies in the department of obstetrics and gynaecology at Vardhman
Mahavir medical college and Safdarjung hospital New Delhi from October 2017 to September 2019.

\section{Inclusion criteria}

Inclusion criteria was the study was conducted on women between 40-65 years who had undergone planned hysterectomy for benign condition.

\section{Exclusion criteria}

Women with genital malignancy, endometriosis, previous pelvic surgery, emergency hysterectomy were excluded.

Each woman was subjected to QOL questionnaires-SF-36 and SQOL-F prior and six months after surgery. Questionnaires used were in their own language, validated and tested in pilot study. The required sample size was 65 (taking 20\% lost to follow up) by using Epi-info software, total 78 eligible women taken in the present study. All data was recorded on excel spread sheet and analysis done by SPSS-21.0 and Wilcoxon-test was used assess the difference and accepted if the $\mathrm{p}$ value was less than 0.05 .

\section{Study tool}

The (SF-36) short form questionnaire used as a health surveys for assessment of quality of life (QOL) was achieved by means of 8 scales (graded 0-100) measuring subjective health, therefore resulting in possible total score ranging 0-800 (from poorest to the best ideal quality of life). The score was assessed by standardized scoring algorithms and summated ratings. Reliability scores in terms of the Cronbach alpha of the SF- 36 in hysterectomy women was 0.78 and $0.88 .^{20}$

The SQOL-F questionnaire was a specific and self-report instrument that focuses on sexual self- esteem, emotional and relationship issues. It consists of 18 items and each item was rated on a six-point response (completely agree to completely disagree). The response categories could be scored either 1 to 6 giving a total score of 18-108. Higher score indicates better female sexual quality of life. ${ }^{21}$ The Cronbach's alpha coefficient was 0.73 and intra class correlation coefficient (ICC) was 0.88 in Maasoumi study. ${ }^{22}$

\section{Study tool Hindi translation}

For our study we had translated the SF-36 and SQOL-F questionnaire from english into hindi. Then, one of the authors back translated draft Hindi version into english and english translation was compared with original english version. Then in the hindi versions corrections were made on the basis of any discrepancy and finalized with the help of hindi expert keeping linguistic and cultural acceptability of terms. Pre-final hindi version of SF-36 and SQOL-F questionnaire was produced. These versions were tested in a pilot study with 10 women and eventually, the final hindi 
version of SF-36 and SQOL-F questionnaire prepared and it was used in this study.

\section{RESULTS}

Table 1 shows maximum number of women in the study were between $40-50$ years of age $(71.79 \%)$. Minimum age in the study was 40 years and maximum age in the study was 65 years. Women who were of lower-class socioeconomic status were 55 contributing $70.51 \%$ of total and 23 women $(29.49 \%)$ belonged to middle class. There is no difference in the area wise distribution of the women $(50.00 \%)$. Most of the women included in the study were illiterates. (66.67\%).

Table 1: Baseline demographic characteristics of study population.

\begin{tabular}{|lll|}
\hline \multicolumn{2}{|l|}{$\begin{array}{ll}\text { Variables } \\
\text { Age distribution (years) }\end{array}$} & Percentage (\%) \\
\hline $40-50$ & 56 & 71.79 \\
\hline $51-65$ & 22 & 28.21 \\
\hline Socioeconomic status & & \\
\hline LC & 55 & 70.51 \\
\hline MC & 23 & 29.49 \\
\hline Address & & \\
\hline Rural & 39 & 50 \\
\hline Urban & 39 & 50 \\
\hline Education & & \\
\hline Illiterate & 52 & 66.67 \\
\hline Literate & 26 & 33.34 \\
\hline
\end{tabular}

Table 2: Indication of hysterectomy.

\begin{tabular}{|lll|}
\hline $\begin{array}{l}\text { Indication of } \\
\text { hysterectomty }\end{array}$ & Frequency & Percentage (\%) \\
\hline Genital prolapse & 44 & 56.41 \\
\hline AUB-L & 34 & 43.59 \\
\hline Total & 78 & 100 \\
\hline
\end{tabular}

Table 3: Route of surgery.

\begin{tabular}{|lll|}
\hline Route of surgery & Frequency & $\begin{array}{l}\text { Percentage } \\
(\%)\end{array}$ \\
\hline $\begin{array}{l}\text { Vaginal } \\
\text { hysterectomy }\end{array}$ & 50 & 67.14 \\
\hline $\begin{array}{l}\text { Total abdominal } \\
\text { hysterectomy }\end{array}$ & 26 & 30.30 \\
\hline $\begin{array}{l}\text { Total abdominal } \\
\text { hysterectomy with } \\
\text { bilateral } \\
\text { salpingoophorectomy }\end{array}$ & 2 & 2.56 \\
\hline Total & 78 & 100.00 \\
\hline
\end{tabular}

Table 2 shows $56.41 \%$ of the women included in study were with prolapse and $43.59 \%$ of women were with AUB-L.
Table 3 shows that $67.14 \%$ women underwent vaginal hysterectomy, $30.30 \%$ underwent TAH, $2.56 \%$ underwent TAH with BSO.

Table 4 and bar shows that all aspects of quality of life improved following hysterectomy with exception of emotional wellbeing. Mean \pm SD of physical health before and after hysterectomy was $\quad 62.76 \pm 5.32$ and $91.96 \pm 2.81$ respectively with a $\mathrm{p}$ value of $<0.001$. Role of limitations due to $\mathrm{PH}$ showed greater improvement after hysterectomy, mean \pm SD of RLDPH before and after hysterectomy was $0 \pm 0$ and $51.67 \pm 3.48$ respectively ( $p$ value $<0.001)$. Mean \pm SD of RLDEH before and after hysterectomy was $0 \pm 0$ and $67.51 \pm 2.58$ respectively ( $p$ value $<0.001$ )

Table 4: Comparison of various parameters of QOLscore before and after hysterectomy $(\mathrm{N}=78)$.

\begin{tabular}{|lll|}
\hline Parameters & Pre-OP & Post-OP \\
\begin{tabular}{|lll} 
Physical \\
health
\end{tabular} & $62.76 \pm 5.32$ & $91.96 \pm 2.81$ \\
\hline RLDPH & $0 \pm 0$ & $51.67 \pm 3.48$ \\
\hline RLDEH & $0 \pm 0$ & $67.51 \pm 2.58$ \\
\hline Energy & $37.53 \pm 1.59$ & $55.19 \pm 1.7$ \\
\hline $\begin{array}{l}\text { Social } \\
\text { functioning }\end{array}$ & $42.21 \pm 38.28$ & $74.17 \pm 4.99$ \\
\hline EWB & $68.4 \pm 2.92$ & $59.94 \pm 2.35$ \\
\hline Bodily pain & $59.87 \pm 4.83$ & $99.49 \pm 3.18$ \\
\hline $\begin{array}{l}\text { General } \\
\text { health }\end{array}$ & $40.38 \pm 1.56$ & $46.6 \pm 4.15$ \\
\hline
\end{tabular}

Mean \pm SD of $\mathrm{E} / \mathrm{F}$ before and after hysterectomy was $37.53 \pm 1.59$ and $55.19 \pm 1.7$ respectively $(\mathrm{p}<0.001)$. Mean \pm SD of SF before and after hysterectomy was $42.21 \pm 38.28$ and $74.17 \pm 4.99$ respectively $(\mathrm{p}<0.001)$. Mean \pm SD of EWB before and after hysterectomy was $68.4 \pm 2.92$ and $59.94 \pm 2.35$ respectively, $\mathrm{p}<0.001$ which shows deterioration of EWB after hysterectomy. Mean \pm SD of $\mathrm{p}$ value before and after hysterectomy was $59.87 \pm 4.83$ and $99.49 \pm 3.18$ respectively $(p<0.001)$. Mean \pm SD of $\mathrm{GH}$ before and after hysterectomy was $40.38 \pm 1.56$ and $46.6 \pm 4.15$ respectively $(p<0.001)$. In Table 5 we compared the SQOL pre and 6 months post hysterectomy. Mean \pm SD of sexual quality of life before and after hysterectomy was $40.7 \pm 2.64$ and $79.04 \pm 4.27$. It was observed that there was a significant improvement in sexual quality of life after hysterectomy ( $p$ value $<0.001$ ).

Table 5: Sexual quality of life before and after hysterectomy ( $\mathrm{N}=78)$.

\begin{tabular}{|lll|}
\hline Sexual quality & Mean \pm SD & P value \\
\hline Pre-op SQOL-F & $40.7 \pm 2.64$ & $<0.0001$ \\
\cline { 1 - 2 } Post-op SQOL-F & $79.04 \pm 4.27$ & \\
\hline
\end{tabular}

The Table 6 shows mean change of sexual quality of life before and after hysterectomy in $\mathrm{VH}, \mathrm{TAH}$ and TAH+BSO was $37.55 \pm 5.6,39.81 \pm 3.31$ and $37.5 \pm 3.54$ 
respectively. There was an improvement in sexual quality of life after hysterectomy but was not statistically significant difference among various routes of hysterectomy $(\mathrm{p}$ value $=0.111)$.

Table 6: SQOL according to route of hysterectomy (N=78).

\begin{tabular}{|lllll|}
\hline Route of hysterectomy & Pre SQOL-F & Post SQOL-F & Mean change & P value \\
\hline VH & $40.92 \pm 3.17$ & $78.47 \pm 4.7$ & $37.55 \pm 5.6$ & 0.111 \\
\hline TAH & $40.38 \pm 1.36$ & $80.19 \pm 3.31$ & $39.81 \pm 3.31$ & \\
\hline TAH with BSO & $40 \pm 0$ & $77.5 \pm 3.54$ & $37.5 \pm 3.54$ & \\
\hline
\end{tabular}

\section{DISCUSSION}

In our study, we found that there was statistically significant improvement in QOL after hysterectomy. The score for 7 out of 8 domains of quality of life questionnaire increased at 6 months post-operatively with an exception of emotional wellbeing which worsened. The improvement in each of the domains pre and postoperative respectively is as follows. $\mathrm{PH}$ improved from $62.76 \pm 5.32$ to $91.96 \pm 2.8$, RLDPH from $0 \pm 0$ to $51.67 \pm 3.48$, RLDEH from 0 to $67.51 \pm 2.58$, energy from $37.5 \pm 1.59$ to $55.19 \pm 1.7$, SF from 42.2 to 74.1 , BP from $59.8 \pm 2.92$ to $99.4 \pm 3.18$, GH from $40.38 \pm 1.56$ to $46.6 \pm 4.15$. Only emotional wellbeing (EWB) worsened from 68.4 \pm 2.92 pre-operatively to $59.9 \pm 2.35$ post operatively which was statistically significant ( $\mathrm{p}$ value $<0.001$ ). Physical recovery and relief of symptoms may explain overall improvement in QOL except EWB since a major surgery has been done involving the uterus and organ central for woman hood that affects her psychologically. The reason for decreased in EWB may be due to feeling of body disfigurement or because of premature ovarian failure which can occur even without oophorectomy

Suken et al reported that significant improvement in all domains of quality of life except bodily pain and its sub domains scores are as follows: PF: 62.1 $\pm 22.6-66.7 \pm 19.4$, SF: $60.8 \pm 13.3-72.6 \pm 14.1$, RLDPH: $28.8 \pm 7.5-45.5 \pm 8.1$, RLDEH: $33.9 \pm 10.6-52.9 \pm 17.2$, mental health $(\mathrm{MH})$ 46.9 $\pm 11.8-57.9 \pm 19.4, \quad$ vitality: $62.1 \pm 13.3-51.6 \pm 12.6$, bodily pain (BP):44.9 $\pm 12.2-61.3 \pm 20.8$, general health $(\mathrm{GH}): 46.7 \pm 13.1-58 \pm 10.7$. $^{1}$

This might me due to increased pain threshold in Indian women. Women had returned to their normal physical health and social function, bodily functions, and general health based on daily activity, amount of time spent on other activities, visiting friends, relatives which was compatible with related research. In present study SQOL$F$ questionnaire was used to assess the sexual quality of life. The mean period of beginning of sexual activity was 3 months after surgery in majority of women. Out of which, $65.5 \%$ women started their sexual activity at 12 weeks after surgery, $24.5 \%$ women at 15 weeks after surgery and $10 \%$ of women at 10 weeks after surgery with a mean of 12.3 weeks It might be due to the fear of vault disruption during intercourse. A study by Briedite et al showed the mean period of beginning of sexual activity after subtotal hysterectomy was 5.15 weeks and after total hysterectomy was 5.78 weeks. ${ }^{18}$ This difference might be due to the cultural differences. In the current study, there was overall improvement in sexual quality of life after planned hysterectomy, mean score before and after hysterectomy was $40.7 \pm 2.64$ and $79.04 \pm 4.27$ respectively and was found to be statistically significant (p value $=0.001)$.

The study by Luis et al showed that improvement in sexual function after hysterectomy which was quite similar to our study. ${ }^{3}$ It showed that quality of life and sexual function improved in both abdominal and vaginal hysterectomy groups (AH and $\mathrm{VH}$ ). Post-operative, $\mathrm{PH}$ : adjusted score for vaginal hysterectomy was $49.5 \pm 1.6$ and for $\mathrm{AH}$, it was $43.8 \pm 1.7$ with a difference of 5.6 points and mental health adjusted score was $51.0 \pm 1.7$ and $59.3 \pm 1.6$ points respectively with difference points of 8.4.

The improvement was mostly due to the removal of pathogenic conditions, personal fear of unplanned pregnancy and its complication, absence of vaginal bleeding, and more time for sexual activities due to cessation of monthly period in prolapsed women improvement may be because of restoration of pelvic anatomy. There was no statistically significant improvement in AUB-L and prolapsed although underlying cause may be different. There was a statistically insignificant improvement observed in SQL in women irrespective of route of hysterectomy. ( $p$ value $=0.111$ ) Similarly Suken et al reported that no signifcant improvement on the participants sexual function score preoperative and one year after hysterectomy. ${ }^{1}$

Another study compared SQOL total hysterectomy of total and subtotal hysterectomy and found no statistically significant improvement in SQOL. The present study showed that there was increased improvement in sexual quality in women who underwent TAH $(39.81 \pm 3.31)$ than TAH with BSO $(37.5 \pm 3.5)$ but it was statistically not significant as the number of women with BSO was less in number. We do not perform BSO routinely in benign condition unless indicated. Moreover, removal of ovaries can cause sudden loss of sex hormone production that might indirectly affect sexual libido and desire. The vast majority of hysterectomies are performed for benign indications, which makes assessment of quality of life in research on hysterectomy an issue of utmost importance. Strength of the study were we followed women for six months after surgery and validated instrument was used and translated to a language that the women could easily understand. 


\section{Limitations}

Limitations of the study were questionnaire method is subjective conception of questions, remembrance failure as well as particularization of answers. In our study, mostly women were illiterate so particularization of answers was not followed properly and might have created verbal bias. The rehabilitation period for women who had undergone hysterectomy in our study, however, did not exceed 6 months.

\section{CONCLUSION}

Hysterectomy improves physical and sexual quality of life post-surgery but sexual quality of life improves (abdominal route>vaginal). However, women need to be provided with adequate emotional support from her gynaecologist.

\section{ACKNOWLEDGMENTS}

Authors would like to expressed our sincere gratitude to all our patients participated in the study.

Funding: No funding sources

Conflict of interest: None declared

Ethical approval: The study was approved by the Institutional Ethics Committee

\section{REFERENCES}

1. Suken G, Kaya AE. Effect of laparoscopic hysterectomy on sexual function and quality life:12months follow up. Cukurova Medical Journal 2018;43:216-17.

2. Chandan J, Asanka G, Chapika G, Bandara S, Dissanayake K. Postoperative Quality of life Assessment after total abdominal hysterectomy. J Gynecol Reproduction Med. 2017;(3):1-4.

3. Luis OCJ, Heleodora P, Lorena VVR. Impact on quality of life and sexual satisfaction of Total abdominal hysterectomy in the absence of Prolapse; Revista Columbian de Obstetric and Gynecol. 2017;68,14-24.

4. Jain S, Pansare SS. Perceptions of Indian women on hysterectomy. International $\mathrm{J}$ of Reproduction, Contraception, Obstetrics and Gynecol. 2017;6:4646-51.

5. Desai S, Shukla A, Nambiar D, Ved R. Patterns of hysterectomy in India: a national and state-level analysis of the Fourth National Family Health Survey (20152016). BJOG. 2019;4(4):72-80.

6. 6) Kramer MG, Reiter RC. Hysterectomy: Indication alternatives and predictors. Am Fram physician 1997;55:827-34.

7. Butt JL, Jeffery ST, Spuy ZM. An audit of indications and complications associated with elective hysterectomy at a public service hospital in South Africa. Int $\mathbf{J}$ Gynaecol Obstet. 2012;116(2):112-6.

8. Nieboer TE, Hendricks JCM, Bongers MY, Vierhout ME, Kluivers KB. Quality of life after laparoscopic and abdominal hysterectomy. Obstetric Gynecol. 2012;119:85-91.

9. Komisurak BR, Frangos E, Whiple B. Hysterectomy improves sexual response addressing crucial omission in literature. J Minim Invasive Gynecol 2011;18:288-95.

10. Sutton C. Past, Present, Future of Hysterectomy. J Minim Invasive Gynecol. 2010;17:421-35.

11. Pauls RN. Impact of gynaecological surgery on female sexual function. Int J Impot Res. 2010;22:105-14.

12. Chen B, Ren DP, Li JX, Li CD. Comparison of vaginal and abdominal hysterectomy. Pak J Med Sci 2014;30:875-9.

13. Iosifescu R, Gidea C, Spanu A, Iordache N, Toderescu $\mathrm{CD}$, Osser G. Assessment of the quality of life following laparoscopic vs abdominal hysterectomy. Romanian J Cognitive Behavioral Therapy and Hyp. 2015;2:1-8.

14. Fram KM, Saleh SS, Sumrein IA. Sexuality after hysterectomy at University of Jordan Hospital: a teaching hospital experience. Arch Gynecol Obstet. 2013;287(4):703-8

15. He H, Yang Z, Zeng D, Fan J, Hu X, Ye Y, et al. Comparison of the short term and the long term outcomes of laparoscopic hysterectomies and abdominal hysterectomies. Chinese J Cancer Res. 2016;28:187-96.

16. Balakrishnan D, Dibyajyoti G. A comparison between Non-Descent vaginal Hysterectomy and Total Abdominal Hysterectomy. J Clin Diagn Res. 2016;10:11-4

17. Danesh M, Hamzehgardeshi Z, Moosazadeh M, Shabani-Asrami F. The Effect of Hysterectomy on Women's Sexual Function: a Narrative Review. Med Arch. 2015;69(6):387-92.

18. Briedite I, Ancane G, RogovskaI, Lietuviete N. Quality of Female Sexual Function After Conventional Abdominal Hysterectomy Three Months observation. Acta Chirurgica Latviensis. 2014;14:26-31.

19. Gendy R, Walsh CA, Walsh SR, Karantanis E. Vaginal hysterectomy versus total laparoscopic hysterectomy for benign disease: a metaanalysis of randomized controlled trials. Am J Obstet Gynecol. 2011;204(5):388.

20. Rodriguez MC, Chedraui P, Schwager G, Hidalgo L, Pérez LFR. Assessment of sexuality after hysterectomy using the Female Sexual Function Index. J Obstet Gynaecol. 2012;32(2):180-4.

21. Polivy J. Psychological reactions to hysterectomy: a critical review. Am J Obstet Gynecol. 1974;118(3):41726.

22. Maasoumi R, Lamyian M, Montazeri A, Azin SA, Aguilar VME, Hajizadeh E. The sexual quality of lifefemale (SQOL-F) questionnaire: translation and psychometric properties of the Iranian version. Reprod Health. 2013;10:25.

Cite this article as: Kumari A, Malik S, Kishore J. Assessment of physical and sexual quality of life in women undergoing planned hysterectomy in tertiary care hospital. Int J Reprod Contracept Obstet Gynecol 2021;10:2448-52. 